\title{
Playing in the Social Media Sandpit
}

by Kate Bunker, ACU

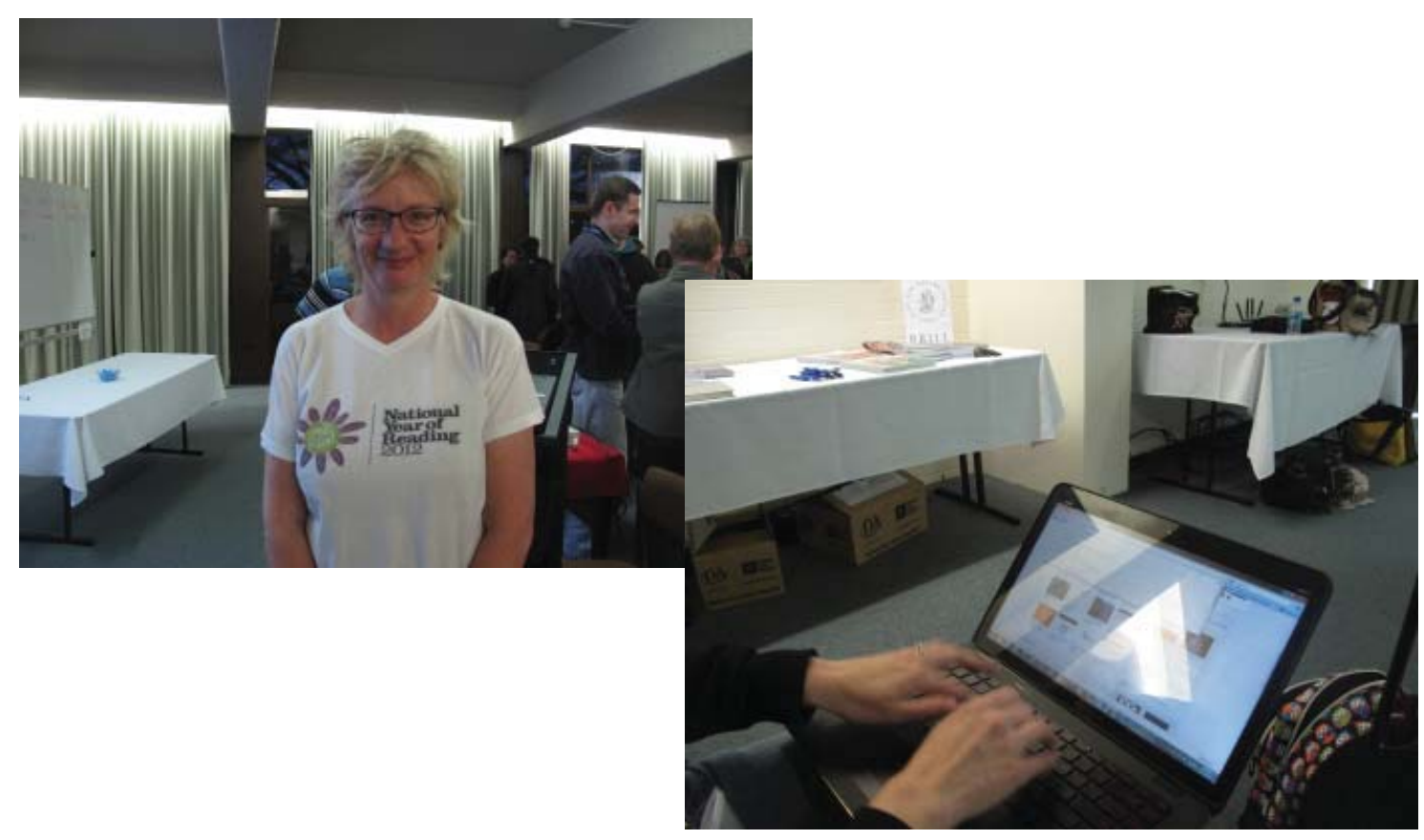

\section{$\oplus A C U$}

'Playing in the social media sandpit' Kate Bunker/ACU Library/12 July 2012

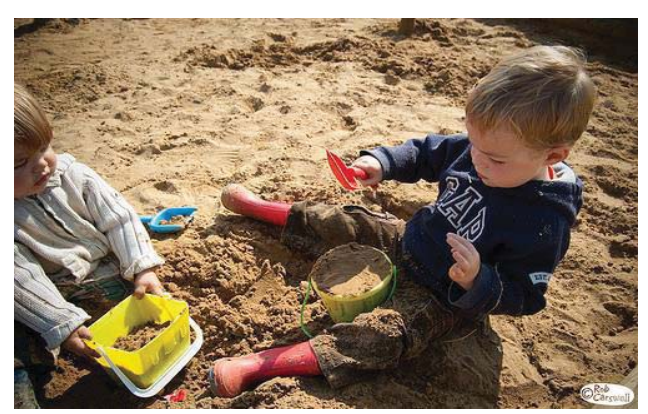




\section{Today...}

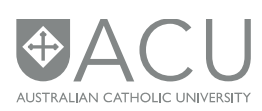

- Practical, hands on

- Challenge you to have a play with one thing you want to look at but haven't had time, support or the courage to play with before...

\section{Survey...}

- Prior to today- sent out a survey to get an idea of what you wanted to cover in this workshop.

- Asked you just a couple of brief questions

- How big is the library you work in?

- How long have you been working in libraries?

- What do you want to learn about in this workshop? 


\section{Part of the survey...}
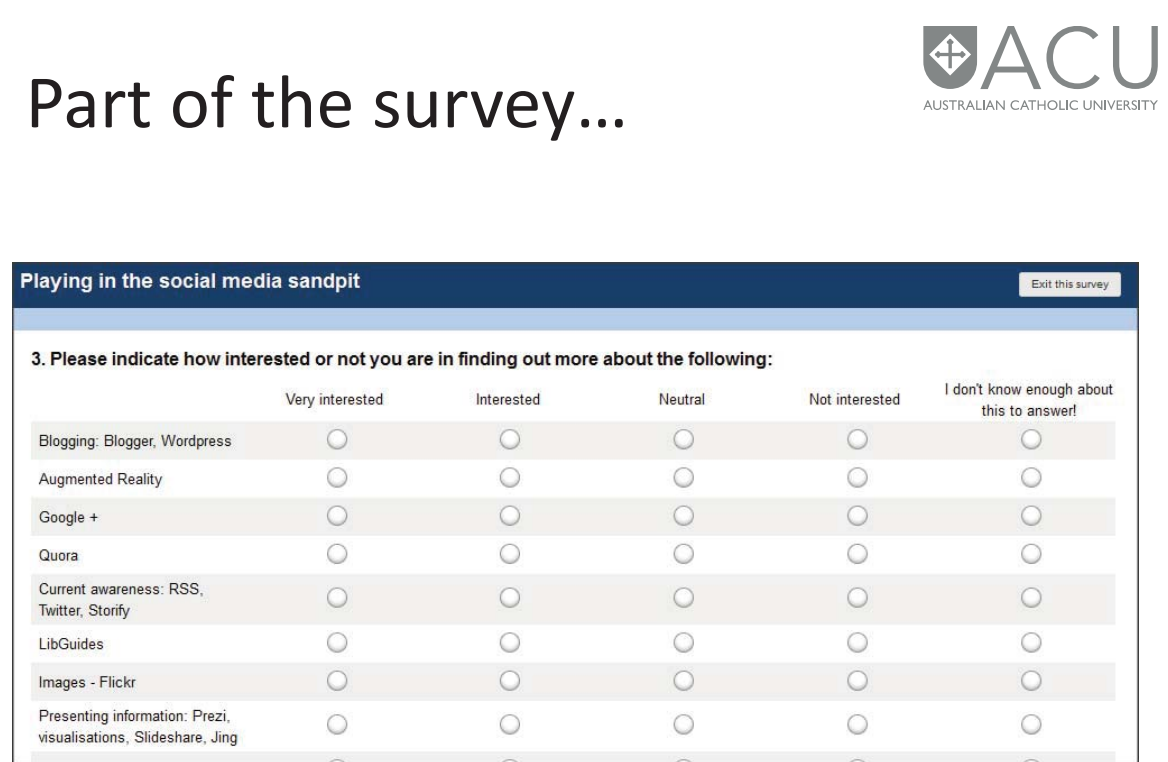

\section{ACU library}

\section{Survey}

- 25 answers to type of library you work in, 6 work "just me", 16 work in a library with 2-5 other people - so do lots of different things, often work alone, different levels and types of support

- 16 out of 25 people have been working in libraries for more than 10 years - lots of experience

- Italics are my conclusions..... ACU/library 


\section{I want to know about...}

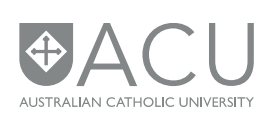

- Blogging....68\%

- Current awareness - RSS, Twitter... 70.8\%

- LibGuides...70.9\%

- Presenting - Prezi, Slideshare...50.6\%

- Filesharing... 76\%

- Organising references...76\%

- Google calendar, Evernote...68\%

- Polls and surveys....66\%

Other suggestions... Facebook (5 responses)

[\% are for very interested and interested]

ACU/library

What do we mean by social media? 


\section{What do we mean by social media?}

- Free? A lot of it

- Reuse?

- In beta - not perfect...

- Remash? Mashup? Use and mix and change?

- Impact of creative commons

- Identity, conversations, sharing, presence, relationships, reputation, groups

\section{ACUllibrary}

\section{Types of social media}

Kaplan and Haenlein (2010), six types of social media:

1. collaborative (eg Wikipedia)

2. blogs and microblogs (WordPress, Blogger, Twitter)

3. content communities (YouTube)

4. social networking sites (Facebook)

5. virtual game worlds (World of Warcraft)

6. virtual social worlds (Second Life) 


\section{The social media revolution}

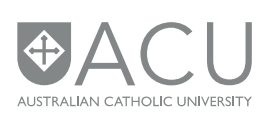

- View this for numbers and scope and awareness, not to say you must be in all of this

- The Social Media Revolution

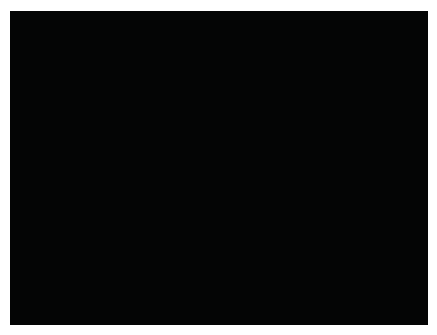

Why Social Media Will

\section{Reshape the 2012 Olympics}

- Facebook 2008 - 100 million users 2012 - 900 million users

- Twitter 2008 - 6 million users 2012 - 500 million users

- YouTube 2008 $2012-800$ million unique visits per month 


\section{Why Social Media Will Reshape the 2012 Olympics

- "The 2012 Olympics in London are being touted by some as the world's "first social Games." While some question just how social they'll actually be, there's no doubt that networks such as Facebook, Twitter and YouTube will play an unprecedented role in how information is disseminated from London, and how the global sports conversation is driven during July and August. And then there are new social media? Pinterest, Google+,

- Web use in general has grown rapidly, too. In 2008, there were about 1.5 billion Internet users globally, according to the International Telecommunications Union, making up about $23 \%$ of the world's total population. By this summer's games, that number will have swelled to about 2.3 billion users making up about a third of the world's total population".

- http://mashable.com/2012/07/08/2012-olympics-social-growth/

\section{ACUllibrary}

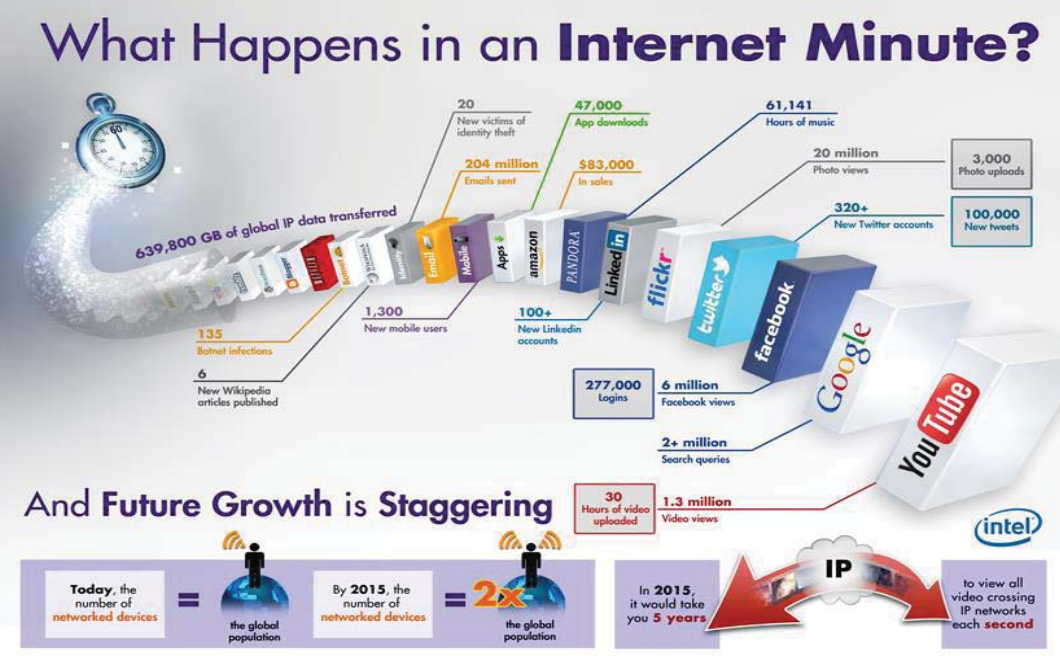




\section{Personal example: Ravelry}
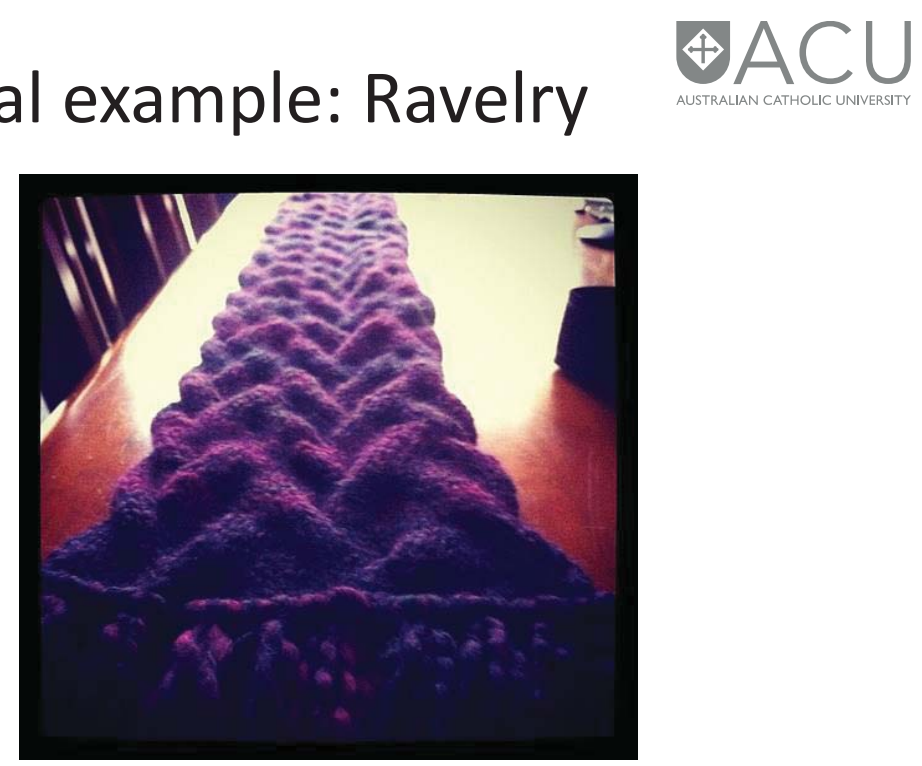

ACU library

\section{Ravelry: a knit \& crochet community}

- Ravelry - my notebook (my area) - can put patterns, my projects (photos, wool, tips, comments with linked patterns from Ravelry), patterns, yarns, people, forums, group, even a shop!

- Not sure how to do a stitch or need something explained? YouTube

- Online forums

- KAL - 'knit a long' - through twitter, buying wool through a friend, common pattern, support

- https://www.ravelry.com ACU library 


\section{Outline for this workshop}

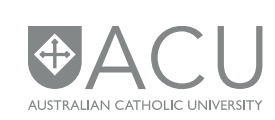

- Play with some of the *things*

- Blogging, create a blog

- FaceBook

- RSS, stay in touch, alerts

- LibGuides, a demonstration of ACU Library use

In the spirit of it all - share \& collaborate \& please ask questions! And answer questions!!

\section{ACUllibrary}

\section{The blog}

- Trax4transition http://trax4transition.blogspot.com.au/

- Your resource... create in WordPress OR Blogger

- Demonstration of how to create a blog

- what is a post,

- how do I publish,

- add pictures. 


\section{Let's start...}
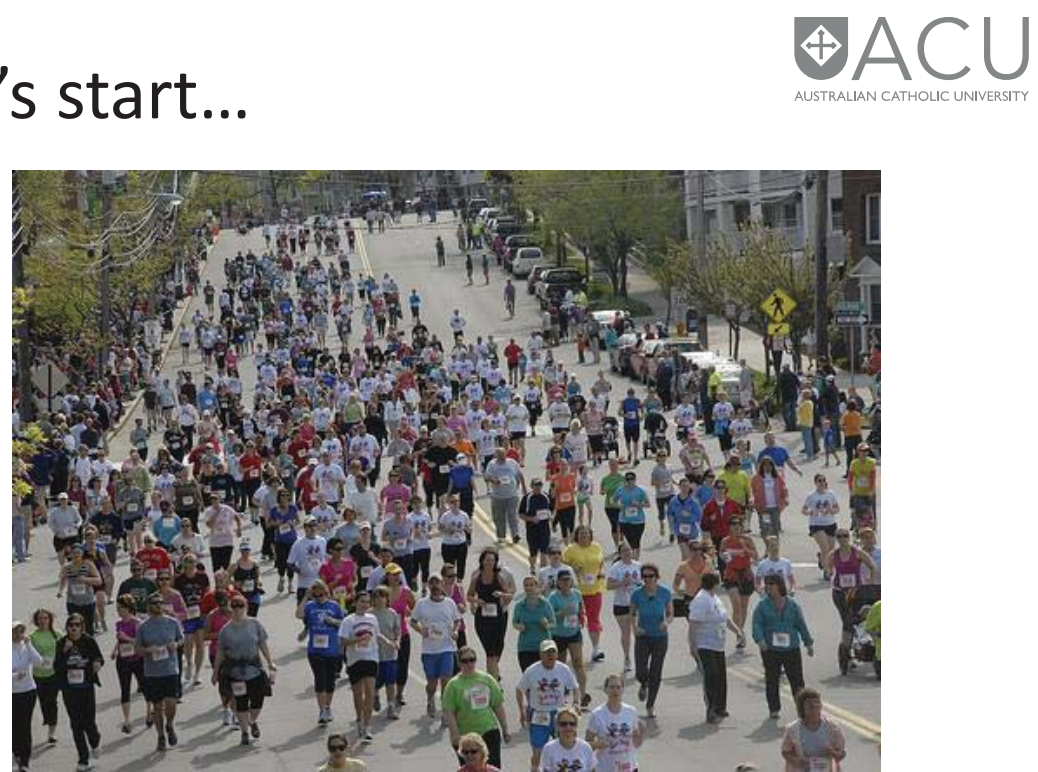

ACU/library

\section{Where do I go from here?}

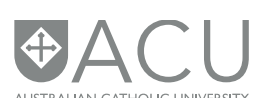

- Try something on a small scale

- Start small

- Start personal -

- start with a personal blog

- what are your interests?

- Don't wait for perfect

- Don't feel alone 


\section{Want to start with books?}

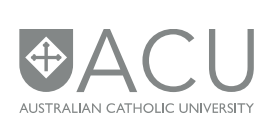

- Try LibraryThing or goodreads - catalogue your books, join a book based social network, reviews, ratings, recommendations

- Follow and read around the National Year of Reading monthly themes \& participate in the monthly tweetups?

ACU library

\section{Options/ideas}

- Do some free online training - 23Things for CPD or some web2.0/23 Things type training

- Read!

- Policy? Look at National Library of Australia Policy on social media/CC

- Use your ANZTLA elist - find people in common... 


\section{Library 2.0, online in October, free!}

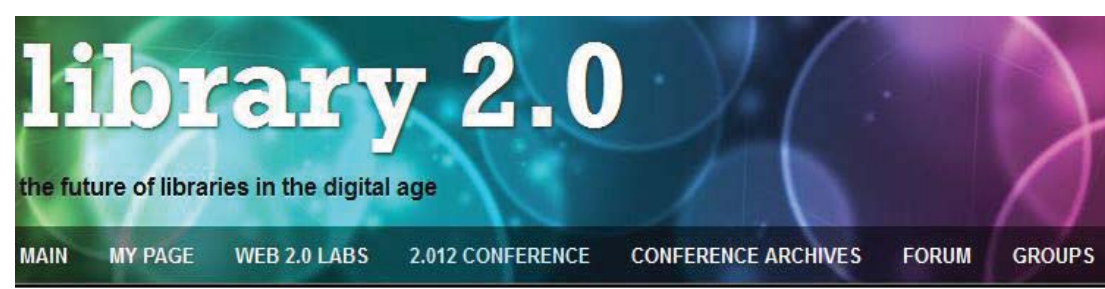

\begin{tabular}{|l|} 
Welcome to Library $2.0 !$ \\
Welcome! Once you join our \\
network, please introduce yourself by \\
going to the Introductions Category in \\
the forum or clicking on the link and \\
creating a new post there. Please \\
note that we have to approve all \\
members to avoid spammers, and \\
that can take up to a day. \\
Glad to have you here!
\end{tabular}

Mamhare

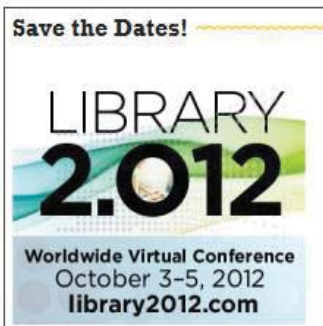

The Library 2.012 Worldwide Virtual

Conference will be held October $3-5$. The conference will be online, in multiple time

zones over the course of two days, and free to attend! The School of Library and

Information Science (SLIS) at San José State

University is the founding conference sponsor.

Register as a member of this Library 2.0 network to be kept informed!

The call for presentation proposals has been issued! Click HERE for more conference details.

\section{ACUllibrary}

\section{Take part in a MOOC? [massive open online course]}
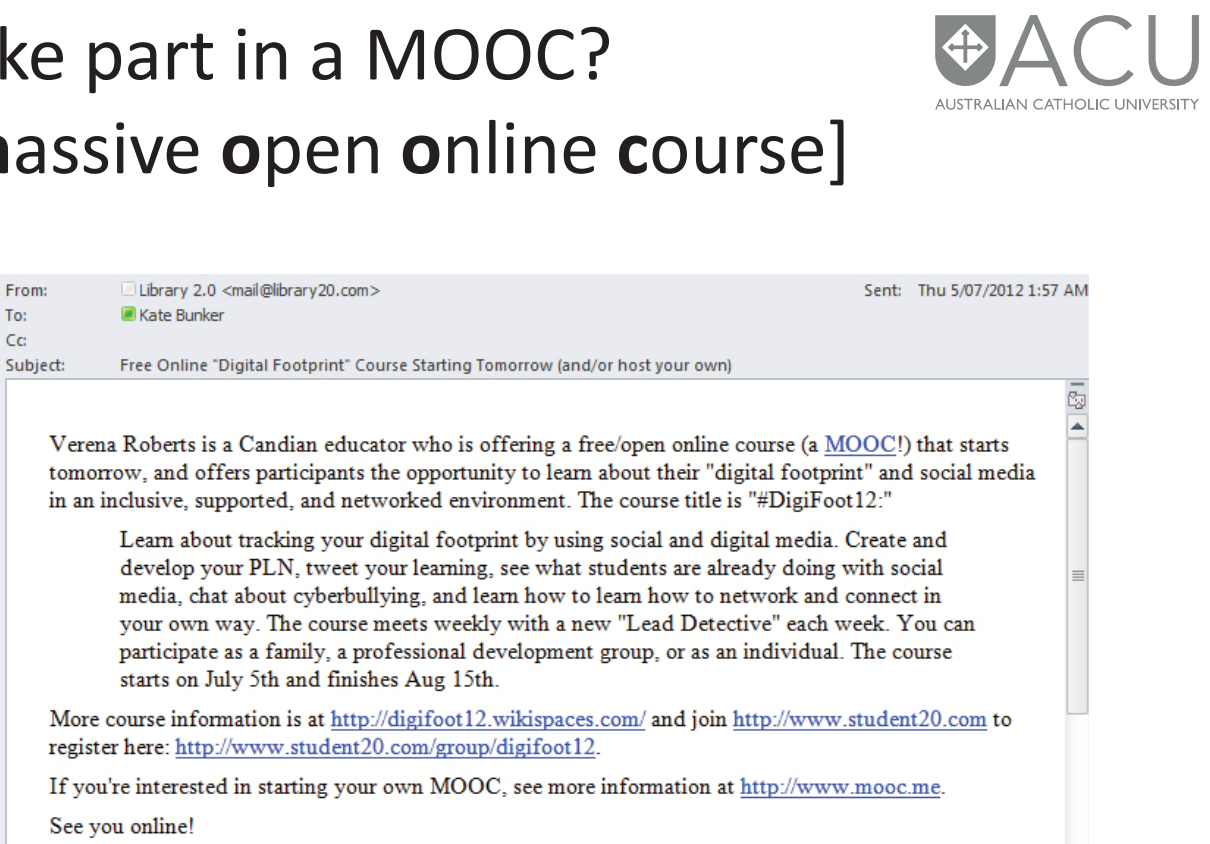

Verena Roberts is a Candian educator who is offering a free/open online course (a MOOC!) that starts tomorrow, and offers participants the opportunity to lear about their "digital footprint" and social media in an inclusive, supported, and networked environment. The course title is "\#DigiFoot 12:"

Leam about tracking your digital footprint by using social and digital media. Create and develop your PLN, tweet your learning, see what students are already doing with social media, chat about cyberbullying, and leam how to leam how to network and connect in your own way. The course meets weekly with a new "Lead Detective" each week. You can participate as a family, a professional development group, or as an individual. The course starts on July 5 th and finishes Aug 15 th.

More course information is at http://digifoot12.wikispaces.com/ and join http://www.student 20 .com to register here: $\mathrm{http}: / /$ www.student 20. com/group/digifoot12.

If you're interested in starting your own MOOC, see more information at http://www.mooc.me. See you online! 


\section{Contact me:}

Kate Bunker

kate.bunker@acu.edu.au

email is probably best

0262091128

- Small steps!

\section{Picture credits}

- Sandpit http://www.flickr.com/photos/lupinoduck/3892851948/

- Survey iStock photo

- Internet minute http://www.antseyeview.com/blog/the-time-for-agilemarketing/

- Scarf - my own pic

- Start http://www.flickr.com/photos/mainerunningphotos/7190515 884/ 